\title{
The Experience of Discrimination and Black-White Health Disparities in Medical Care
}

\author{
Louis A. Penner, \\ Wayne State University, University of Michigan \\ John F. Dovidio, \\ Yale University \\ Donald Edmondson, \\ University of Connecticut \\ Rhonda K. Dailey, \\ Wayne State University \\ Tsveti Markova, \\ Wayne State University \\ Terrance L. Albrecht, and \\ Wayne State University \\ Samuel L. Gaertner \\ University of Delaware
}

\begin{abstract}
The current study of Black patients focuses on how discrimination contributes to racial disparities in health. The authors used a longitudinal methodology to study how perceived past discrimination affects reactions to medical interactions and adherence to physician recommendations. In addition, they explored whether these reactions and/or adherence mediate the relationship between discrimination and patients' health. The participants in this study were 156 Black patients of low socioeconomic status at a primary care clinic. Patients completed questionnaires on their current health, past adherence, and perceived past discrimination. Then, they saw a physician and rated their reactions to the visit. Four and 16 weeks later they reported on their adherence to physician recommendations and overall health. Perceived discrimination was significantly and negatively associated with patient health, reactions to the physician, and adherence. Path analyses indicated that adherence mediated the relationship between discrimination and patient health, but patient reactions to the interaction did not.
\end{abstract}

\section{Keywords}

discrimination; health care disparities; patient compliance

The focus of the current work is on how perceptions of racial discrimination contribute to Black-White health disparities in the United States. Previous research has revealed a relatively strong negative association between the self-reported experience of discrimination

(C) 2009 The Association of Black Psychologists

Correspondence should be addressed to Louis A. Penner, Communication and Behavioral Oncology Program, Karmanos Cancer Institute, Wayne State University, 4100 John R., Detroit, MI 48201; pennerl@karmanos.org.. 
among Blacks and their physical and mental health (Williams, Neighbors, \& Jackson, 2003; Williams, Yu, Jackson, \& Anderson, 1997). However, the mechanisms responsible for this relationship remain unclear. Some researchers (e.g., Clark, Anderson, Clark, \& Williams, 1999; Mays, Cochran, \& Barnes, 2007) argue that race-based discrimination increases allostatic load on the body, which makes people more susceptible to disease. Other researchers posit a more indirect path, in which discrimination forces people who are the objects of this bias to live in environments that are psychologically and physically unhealthy, and this contributes to poorer health among Blacks (Cozier et al., 2007; DiezRoux et al., 2001).

While not disputing these explanations, the present research adopts a different approach to the role of perceived discrimination in Black-White health disparities. Our specific interest is in how perceived discrimination may affect Black patients' responses to the health care they receive. The core premise of our approach is that historical and contemporary racial discrimination shapes the perceptions and expectations of Blacks in ways that have significant impact on health and health care-related behaviors. Specifically, we propose that the pervasive history of race-based prejudice and discrimination in the United States leads to a sense of wariness and mistrust among many Black patients. These feelings negatively affect Black patients' responses to medical interactions and their health behaviors related to those interactions (Dovidio et al., 2008), which in turn can have deleterious health consequences for Black patients. Of special interest in the current work was how past experiences with discrimination may directly and indirectly influence Black patients' adherence, that is, their willingness to follow the recommendations of their physician. The present research thus investigated the relationships among Blacks' previous experience with discrimination, reactions to medical interactions, adherence to physician recommendations, and their health. However, rather than using survey responses to general questions about health, health care, and health-related behaviors, we examined these relationships in the context of actual patient-physician interactions.

There is little question that negative racial stereotyping and expressions of prejudice among Whites have declined dramatically over the last 50 years (Bobo, 2001; Dovidio \& Gaertner, 2004; Schuman, Steeh, Bobo, \& Krysan, 1997). However, racial bias has not disappeared from the United States. Rather, the nature of racial biases of Whites toward Blacks in the United States has changed from being blatant and overt to bias that is subtle and often unintentional. More specifically, Dovidio and Gaertner (2004; also Gaertner \& Dovidio, 1986) propose that today a substantial portion of White Americans are "aversive racists." That is, they are individuals who endorse principles of fairness and equality at an overt, conscious level but also harbor covert or unconscious negative attitudes toward Blacks (see also Greenwald, Nosek, \& Banaji, 2003; see also McConahay, 1986; Sears, Henry, \& Kosterman, 2000, for related research on modern and symbolic racism). Aversive racists generally do not discriminate against Blacks when appropriate behavior is clearly defined and discrimination would be obvious. They do, however, tend to discriminate against Blacks when the appropriate behavior is less clearly defined or when bias can be attributed to some factor other than race (see Dovidio \& Gaertner, 2004, for a review). In addition, in interracial interactions, aversive racists tend to exhibit positive behaviors toward Blacks in their more controllable (e.g., verbal) responses, reflecting their explicit attitudes, but they display relatively negative orientations in their less controllable (e.g., nonverbal) behaviors, reflecting their implicit negative attitudes (Dovidio, Kawakami, \& Gaertner, 2002; McConnell \& Leibold, 2001).

One consequence of the denial of bias by aversive racists even as they discriminate against Blacks in subtle but influential ways (see Sue et al., 2007) is the development of high levels of vigilance and wariness among Blacks in interracial interactions with Whites (Dovidio, 
Gaertner, Kawakami, \& Hodson, 2002). Moreover, these expectations of bias sensitize Blacks to subtle cues of negativity from Whites (Johnson, Ashburn-Nardo, Spicer, \& Dovidio, 2008; Pearson et al., 2008; Shelton, Richeson, \& Salvatore, 2005; see also Shelton, Richeson, \& Vorauer, 2006). Thus, the experience of discrimination either in subtle, unintentional or blatant, intentional forms contributes to a general distrust that Blacks have of Whites, in general, and of prominent American institutions. Indeed, representative surveys reveal that Blacks perceive much higher levels of discrimination in the United States than do Whites (Saad, 2007) and have substantial levels of mistrust for Whites in general (Anderson, 1996) and, in particular, for institutions such as government and law enforcement (Crocker, Luhtanen, Broadnax, \& Blaine, 1999; Phelps, Taylor, \& Gerard, 2001).

This mistrust extends to health care as well (Institute of Medicine, 2003). National surveys find that Blacks are significantly more likely than Whites to believe that their race negatively affects their health care (Johnson, Saha, Arbelaez, Beach, \& Cooper, 2004), and Blacks are less trusting of their physicians than are Whites (Halbert, Armstrong, Gandy, \& Shaker, 2006; Lee, Tamayo-Sarver, Kineer, \& Hobgood, 2008). In a national survey reported by Malat and Hamilton (2006), 57\% of Blacks reported that discrimination occurs "often" or "very often" in Blacks' interactions with White physicians. Thorburn and Bogart (2005) conducted a telephone survey of Black women who had used family planning services; $67 \%$ reported race-based discrimination when using these services. In a related study, Bird and Bogart (2001) found that $63 \%$ of their Black respondents perceived discrimination in their interactions with their health care provider.

This mistrust and expectation of stigmatization, both generally and in the context of medical encounters, can have a significant impact on the utilization of services among Blacks. For example, Crawley, Ahn, and Winkleby (2008) reported that Blacks who perceive higher levels of medical discrimination are less likely to get cancer screenings. Other research shows that perceived general discrimination is associated with lower levels of health-related behaviors such as cholesterol and diabetic testing and receiving flu shots (Blanchard \& Lurie, 2004; Trivedi \& Ayanian, 2006). The present research examines whether prior experiences with discrimination may also predict how well Black patients adhere to specific physician recommendations.

The current research extends this previous work by examining (a) the extent to which perceptions of prior discrimination are associated with Black patients' reactions to a specific medical interaction, (b) how perceived discrimination and reactions relate to the patients' subsequent adherence to the doctor's recommendations, and (c) how perceived discrimination, patient reactions, and adherence relate to the patients' health.

Our sample was a group of Black patients at a primary care facility in a large urban center with a predominantly Black population. In order to try to draw links among the variables of interest, we used a longitudinal methodology, in which we assessed patients' perceived past discrimination and their past adherence to medical recommendations. Then, we assessed patient reactions to an interaction with a physician and measured subsequent adherence to physician's recommendations and patient self-reported health 4 weeks and 16 weeks later.

The first set of hypotheses concerned the relations between discrimination and (a) health, (b) reactions to the interaction, and (c) adherence. Consistent with previous research showing an association between past discrimination and health (Hausmann, Jeong, Bost, \& Ibrahim, 2008; Mays et al., 2007; Williams et al., 2003) we hypothesized, first, that there would be a negative association between patients' self-reports of past discrimination and their selfreports of general health. Second, previous research shows that Blacks' experiences with 
past discrimination and expectation of bias relate to more negative reactions to specific interpersonal encounters in which concerns about bias are aroused (Johnson et al., 2008) and to less patient satisfaction in medical interactions (Benkert, Peters, Clark, \& Keves-Foster, 2006). Thus, we hypothesized that Black patients who reported experiencing greater discrimination previously in their life would react less positively to a specific medical interaction. Third, on the basis of prior research that finds negative associations between perceived discrimination and Black patients' willingness to engage in appropriate healthrelated behaviors (e.g., Ryan, Gee, \& Griffith, 2008), we hypothesized a significant negative association between past perceived discrimination and (a) past adherence to the recommendations of physicians and (b) adherence to the recommendations of the specific physician the patient had just seen.

The current research further extends previous work by using a longitudinal methodology to focus on certain aspects of health care that potentially mediate the overall relationship between perceived discrimination and Black patients' health. We first investigated whether prior experiences with discrimination would predict patients' adherence to the specific physicians' recommendations during the clinic visit. We then also explored the role of patients' reactions to a specific medical interaction as a mediator of the hypothesized negative relationship between perceptions of past discrimination and adherence to the physician's recommendation. The relatively limited literature that has explored the effects of Black patients' satisfaction with a medical encounter and subsequent adherence yields mixed results. Some researchers (e.g., Bogart, Bird, Walt, Delahanty, \& Figler, 2004; Harris, Luft, Rudy, \& Tierney, 1995; Wroth \& Pathman, 2006) have found a positive association between patient satisfaction and adherence, but others have not (e.g., Campbell, Auerbach, $\&$ Kiesler, 2007). Nevertheless, given at least some evidence of the relationship in previous research, we predicted a positive association between favorable patient reactions to the interaction and patient adherence. Related to this, we predicted that patient reactions would mediate the relationship between past discrimination and adherence to medical recommendations. We additionally hypothesized that adherence to the physicians' medical recommendations would be positively related to patients' health (Morisky, Ang, KrouselWood, \& Ward, 2008). More importantly, we also predicted that adherence would mediate the relationship between perceived discrimination and patient health. That is, the distrust created by high levels of past discrimination would reduce adherence, which would, in turn, contribute to poorer health among Black patients.

\section{METHOD \\ PARTICIPANTS}

The patients were 156 individuals (119 women and 38 men) with appointments at a primary care clinic in a large midwestern city. All patients self-identified as Black or African American and had some form of health insurance. The patients' average age was 43.69 years (standard deviation $[S D]=13.66$ ). With regard to education, $29.2 \%$ of the patients who responded had not graduated from high school, another $21.4 \%$ had graduated from high school, and the remainder had at least some college education. Among patients who reported their income, $45.2 \%$ had annual family incomes of less than $\$ 20,000 ; 30.0 \%$ had incomes between $\$ 20,000$ and $\$ 40,000$; and $24.8 \%$ had annual incomes of more than $\$ 40,000$ per year. Patients received $\$ 20.00$ gift cards for their participation at the clinic and $\$ 15.00$ gift cards for completion of each of the follow-up questionnaires, 4 and 16 weeks after their visit to the clinic. 


\section{PROCEDURE}

When patients arrived for a scheduled appointment with a physician, they were approached by a staff member and asked if they would be willing to speak to someone about a research study. If they agreed, they were provided an explanation of the study and then signed an informed consent and a HIPAA release for examination of their medical records. In all, 73\% of the patients approached agreed to be in the study.

Each patient saw 1 of 19 physicians who were residents in family medicine at the clinic. Two physicians self-identified as White, 1 as Black, and 16 as East Asian (all but 1 from India or Pakistan). Ten of the residents were women, and the residents' average age was $31.00(S D=3.48)$. All of the East Asians and one of the White physicians had received their medical training outside the United States. The distribution of ethnicity and place of training of the physicians is quite typical for clinics that serve low income, minority patient populations in the United States (Institute of Medicine, 2003). Physicians were offered a $\$ 50.00$ gift card as an incentive for their involvement in the study.

Patients completed questionnaires four times: before seeing the physician, immediately after seeing the physician, and then 4 and 16 weeks after the visit. The last two questionnaires were mailed to the patients' residences and returned in preaddressed and stamped envelopes. Of the 156 patients who completed the preinteraction questionnaires, all but two completed one of the postinteraction questionnaires (i.e., Patient-Perception of Patient-Centeredness Scale [PCC] or team perceptions). The first follow-up questionnaire was returned by 117 patients (76\%), and the second was returned by 100 patients (65\%). A small number of returned patient questionnaires (less than 5\%) contained missing responses to specific items. We opted not to impute missing values for measures. There were no differences in scores on the pretest measures between the patients who completed just the postinteraction questionnaires and those who also completed follow-up questionnaires.

Preinteraction measures-The preinteraction measures were patients' self-reports of their (a) past adherence to physicians' medical recommendations, (b) health, and (c) past experiences with discrimination in several different areas.

To assess patients' past adherence to recommendations from their physicians, we used items from the Medical Outcomes Study (MOS) adherence questionnaire developed by RAND Health (Hays et al., 1994). This instrument uses a six-point response format (with choices ranging from none of the time to all of the time) to assess the frequency of general adherence to physician recommendations and adherence to specific health-related behaviors. Because we would have no way of knowing the specific recommendations made by the physicians, we were only interested in the general adherence items. Although Hays et al. (1994) reported high internal consistency for the five general adherence items, in our sample, we found low internal consistency if we included the two items that contained negative wording about adherence. Therefore, we deleted these negative items and used only the positively worded items in our measure of general adherence. The coefficient alpha for these three items was .72.

Self-reported health prior to the interaction was assessed with the MOS 20-Item Short Form Health Survey (SF-20; Ware, Sherbourne, \& Davies, 1992). This is a version of the widely used SF-36, developed by Ware and associates for RAND Health. It assesses physical functioning, role functioning, social functioning, mental health, pain (one item), and current general health status. All subscales (except, of course, the one-item pain subscale) have good internal consistency, and there is considerable evidence of their construct validity (Ware et al., 1992). The general health subscale was used as our measure of self-reported health. In our sample, this subscale had a coefficient alpha of .84. The originators of the 
SF-20 did not address the problem of socially desirable responding, but other researchers (e.g., Buskirk \& Stein, 2008) suggest that the use of mail questionnaires reduces this threat to the scale's validity. As noted earlier, we used mail questionnaires to assess postinteraction health status.

We used a modified version of a measure reported by Brown (2001) to assess perceived past discrimination. Respondents answered whether they had ever experienced discrimination in each of the six areas (in their jobs, when applying for a job, in dealings with the police, in education, obtaining housing, when dealing with neighbors) and in a seventh area directly relevant to the current context (in their medical treatment). If respondents answered "yes" to an item, they were then asked whether this was because of their race/ethnicity or some other reason (e.g., gender, appearance). In each area of discrimination, the majority of the respondents who said they were the victims of discrimination attributed it to their race/ ethnicity. There was no clear second choice in attributions to discrimination among the responses. In all, $44 \%$ of the patients reported that they had experienced no discrimination in any of the seven areas, $17 \%$ reported discrimination in one area, and the remaining $39 \%$ reported discrimination in at least two of the areas.

We examined the associations among the responses to the seven items and found that there was fairly high internal consistency for a seven-item, yes-no scale (split-half reliability $=$. 61). Exploratory analyses also revealed that all seven items had roughly equivalent correlations with the other variables of interest. Therefore, we used the sum of responses to the seven discrimination items as our measure of perceived past discrimination.

At the end of the pretest questionnaire, patients provided demographic information (age, gender, education, family income). They then had their scheduled interaction with the physician. Immediately after their interaction with the physician, patients' reactions to the interaction were assessed. This was done at the clinic but out of the sight of physicians, nurses, or other clinic staff.

Postinteraction measures-Immediately following patients' interactions with their physician, we assessed their responses to the interaction in terms of their satisfaction and feelings of being "on the same team" with the physician.

Although there are a large number of ways to measure patients' satisfaction with medical interactions, we opted to focus on patients' perceptions of how "patient-centered" the interaction was. According to Epstein et al. (2005), a patient-centered interaction is one in which the physician "provide(s) care that is concordant with the patient's values, needs and preferences, and that allows patients to provide input and participate actively in decisions regarding their health and health care" (p. 1516). Patient-centered communication is broadly accepted as a central component of high-quality health care and strongly associated with patients' satisfaction with their health care (Epstein et al., 2005; Little et al., 2001; Mallinger, Griggs, \& Shields, 2005).

Patients completed the 14-item PCC (Stewart et al., 2000) plus one additional item that directly asked them how satisfied they were with the interaction they had just completed. The PCC presents statements about the interaction (e.g., "To what extent did the doctor explain treatment?") and uses a four-point response format, with alternatives ranging from completely to not at all. Stewart et al. (2000) report that the PCC measure has good internal consistency, and scores on the scale are significantly associated with patient health outcomes and efficient use of health services. In the present instance, the total PCC scale plus the additional satisfaction item produced highly reliable scores. The coefficient alpha for this measure was .93 . 
Gaertner and Dovidio (2000) have demonstrated that when members of different racial/ ethnic groups interact, a sense of their all being on the same team or having a common purpose is associated with less intergroup bias and more positive relationships among members of the different groups. Therefore, five items intended to assess the extent to which the patients saw themselves as being on the same "team" or as partners with the physician during the interaction were developed specifically for this study. For example, one item read, "The doctor and I worked together as a team to solve my medical problems."

Preliminary analyses showed that the two negatively worded team items correlated very weakly with the three positively worded items. Therefore, only the positively worded items were used to create the team scale. The coefficient alpha for this measure was .86 .

Follow-up-Four weeks and 16 weeks after an interaction took place, patients received in the mail the same self-report adherence measure and health measure (the SF-20) as they had completed in the pretest. However, now patients were asked to complete them in terms of their adherence to the recommendations from their last interaction with the physician and their health status at that time. They returned the measures in a self-addressed, stamped envelope. Gift cards were mailed to patients when the questionnaires were received.

Medical chart reviews-After all the self-report data were collected, a detailed review of each patient's medical record was conducted. In the present context, the medical record information was used primarily to see whether the discrimination-health relationship would also be found when an objective rather than self-report measure of health was used. In these medical reviews, coders examined all information contained in the charts prior to and 1 month after the visit to the clinic. Information was obtained on patients' blood pressure (readings on two separate days), height, weight, and the presence or absence of chronic diseases such as asthma, high cholesterol, diabetes, and coronary heart disease.

\section{RESULTS \\ OVERVIEW OF ANALYSES}

The analyses were carried out in stages. First, we tested the hypotheses about bivariate relationships between perceived discrimination and health, reactions to the interactions, and adherence. After we had conducted the tests of these hypotheses, we tested the hypotheses about bivariate relationships among the variables that might mediate the association between perceived discrimination and health. Finally, we conducted path analyses to test the hypothesized direct and indirect effects of discrimination on the patients' health. Unless otherwise noted, the alpha level for all tests of significance was .05.

When a significant bivariate relationship was found, we examined whether any of the demographic variables was significantly related to either of the variables involved in the relationship. If they were, we conducted a partial correlation between those variables with the demographic covariate partialled out. In addition, we addressed the issue of dependency in some of the measures. The specific problem was that because several of the physicians interacted with more than one patient, the measures of patient satisfaction and team perceptions were nested within physicians. This might have created dependency in responses to the satisfaction and team measures among patients who saw the same physicians. To deal with this potential problem, we used the general estimating equation (GEE) in SPSS to conduct secondary analyses of relationships involving the satisfaction and team measures. GEE is a form of hierarchical linear modeling that provides tests of associations between variables in which dependency in one or more of the variables is controlled (Liang \& Zeger, 1986). We found no instances where the GEEs yielded substantially different findings from the product moment correlations with regard to either 
magnitude of the association or tests of significance. Therefore, in the interest of clarity, we only report the product moment correlations. Finally, we conducted separate preliminary analyses for male and female patients. Our preliminary analyses indicated that patient gender did not significantly moderate the relationships we studied; the signs and general magnitudes of the correlations did not differ systematically across gender. Therefore, we collapsed across gender in the major analyses.

\section{DEMOGRAPHIC CORRELATES}

Income was positively correlated with general health on the pretest, $r(154)=.32, p<.001$; on the 4-week follow-up, $r(106)=.25, p=.011$; and on the 16-week follow-up, $r(90)=.28$, $p=.007$. None of the demographic variables was related to perceived discrimination.

Similarly, the relationships between the demographic variables and reactions to the specific interactions were all nonsignificant. Age was positively correlated with adherence on the 16week follow-up questionnaire, $r(100)=.22, p=.030$.

\section{PERCEIVED DISCRIMINATION}

Table 1 presents the correlations between perceived discrimination and the measures of general health, reactions to the interaction (i.e., patient satisfaction and team perceptions) and adherence, and the correlations among these measures.

Health-The first hypothesis concerned the relationship between the patients' self-reports of being the target of discrimination and their health. On the basis of prior research, we posited that the higher the patients scored on the perceived discrimination measure, the poorer would be their health. We tested this hypothesis by using pretest, 4-week follow-up, and 16-week follow-up scores on the general health subscale of the SF-20 as the health measures. The total score on the perceived discrimination measure was significantly and negatively correlated with the general health subscale at the pretest, 4-week follow-up, and 16-week follow-up: $r \mathrm{~s}=-.28,-.37$, and -.28 , respectively; all $p \mathrm{~s}<.05$. That is, the higher the perceived discrimination, the poorer the patients' self-reported general health.

Additionally, perceived discrimination was significantly and positivelyassociated with the total number of chronic illnesses the patients had (assessed from the medical records), $r(140)=.20, p=.018$. More specifically, there were significant positive associations between perceived discrimination and the presence/absence of: diabetes, $B(1,141)=.32, p$ $<.02$, and chronically high cholesterol, $B(1,141)=.24, p<.05$. These findings provide further support for our first hypothesis. Although mental health was not the main focus of this study, we note that perceived discrimination was also related to the patients' mental health. Specifically, perceived discrimination was significantly and negatively correlated with the mental health subscale of the SF-20 measured at the pretest, 4-week follow-up, and 16-week follow-up: $r \mathrm{~s}=-.30,-.23$, and -.23 , respectively; all $p \mathrm{~s}<.05$.

Because patient income was also significantly correlated with general health on the pretest and the two posttests, we conducted partial correlations between discrimination and health with income partialled out. Partialling out income did not meaningfully change the discrimination-pretest health correlations: They all remained significant.

Reactions to the medical interactions-We hypothesized that perceived discrimination would be negatively associated with patients' reactions to the specific medical interaction in which they participated. The first analysis examined the relationship between discrimination and patient satisfaction. The correlation was significant, $r(131)=-$. $24, p=.005$. That is, as predicted, the greater the perceived past discrimination, the less the patients' satisfaction with their immediate medical interaction and the specific doctor. Also, 
the greater the perceived discrimination, the lower the patients' scores on the perceived team measure, $r(141)=-.21, p=.013$. Thus, the second hypothesis was also confirmed.

Adherence-The third hypothesis concerned the relationship between perceived discrimination and adherence to the physicians' recommendations. We found, as predicted, that greater perceived discrimination was related to less prior adherence, $r(138)=-.26, p=$. 002 , and to less adherence at the 4-week follow-up, $r(107)=-.27, p=.004$, and at the 16week follow-up, $r(91)=-.31, p=.003$. Partialling age out of the discrimination-adherence relationship for the 16-week follow-up did not meaningfully change it, $r_{\mathrm{par}}(88)=-.29, p=$. 006 .

\section{SATISFACTION, ADHERENCE, AND HEALTH}

In the next set of analyses, we examined the bivariate relationships among the variables that might mediate the relationship between discrimination and health. We predicted that patient reactions to the interaction would be significantly associated with postinteraction adherence. This hypothesis was only partially confirmed. A significant positive association was found between patient satisfaction and adherence at the 4-week follow-up, $r(110)=.30, p=.001$. The relationship between satisfaction and adherence at the 16-week follow-up approached significance at the alpha level established for this study, $r(94)=.18, p=.076$. Although not hypothesized, patient satisfaction with the interaction was also significantly associated with health 4 weeks after the visit to the clinic, $r(104)=.21, p=.032$. Team perceptions were unrelated to subsequent adherence or health.

The prediction that postinteraction adherence would be significantly associated with health was also partially confirmed. That is, adherence at the 4-week follow-up was significantly and positively related to general health at this time, $r(108)=.29, p=.003$, and at 16 weeks after the visit to the clinic, $r(84)=.21, p=.053$. However, adherence and health at the 16week follow-up were not significantly related. Only one of these relationships changed when the demographic variables were partialled out. When income and age were partialled out of the adherence at 4 weeks to health at 16 weeks relationship, the strength of the association actually increased, $r_{\mathrm{par}}(77)=.23, p=.045$.

\section{MEDIATIONAL ANALYSES}

In the final set of analyses, we conducted empirical examinations of possible mediators of the relationship between perceived discrimination and patients' general health at the time of the follow-ups. Recall, we found that (a) perceived discrimination was significantly associated with general health after the interactions, patient reactions to the interactions, and adherence to physician recommendations; (b) patient satisfaction with the interaction (but not team perceptions) was significantly related to adherence and general health at the 4week follow-up; and (c) adherence at the 4-week follow-up was significantly related to general health at both the 4-week follow-up and the 16-week follow-up. These bivariate associations led us to examine if patient satisfaction and/or adherence mediated the relationship between perceived discrimination and the patients' health after the interactions.

To examine these mediational effects, Amos 16 (Arbuckle, 2007) was used to conduct path analyses on the variables of interest in the study. Because missing data were not systematic, listwise deletion was used prior to model testing. All remaining data were screened prior to the analyses to assure normality; all distributions were sufficiently normal to assume multivariate normality (Kline, 2005). Multiple fit indices were used to assess model fit, and standard cutoff recommendations (Hu \& Bentler, 1999) were employed. The model chisquare statistic was used to determine the fit of each model to the observed data, as was the normed chi-square statistic (Bollen, 1989). In structural equation modeling, a nonsignificant 
model chi-square $(p>.05)$ suggests good model fit, as it indicates that the model does not differ significantly from the observed data. Other standard fit indices used to evaluate the models were the comparative fit index (CFI) and root mean square error of approximation (RMSEA), which are based on the noncentrality parameter. A CFI greater than .95 and an RMSEA of .05 or less suggest a good fit (Hu \& Bentler, 1999). Significance tests for indirect effects were constructed by obtaining parameter standard errors using bootstrap resampling in Amos 16 (Nevitt \& Hancock, 2001).

We tested several models in which patient satisfaction was posited as mediating the discrimination post interaction health relationship. None of the models produced even a marginally good fit to the observed data. Thus, we abandoned any attempts to develop models that focused on patient satisfaction as a mediational mechanism.

We had much more success with models that posited a mediational role for adherence to physician recommendations. Figure 1 presents a model based on the conceptual framework that guided this work. The model posits, first, a direct effect of perceived discrimination on the health of Black patients. In addition, perceived discrimination has indirect effects on Black patients' health; it affects both adherence to medical recommendations, in general, and adherence to physician recommendations that were made in a specific interaction. General adherence influences adherence to physician recommendations in a specific interaction, which in turn affects Black patients' health. When we tested the path model based on this conceptualization, it produced a very good fit to the observed data: $\chi^{2}(1, N=$ $68)=1.46, p=.23 ; \mathrm{CFI}=.99$; RMSEA $=.08$ (90\% confidence interval $[\mathrm{CI}]=0.00-0.35)$.

When we examined the individual paths, the path from perceived discrimination to adherence at the 4-week follow-up was found to be nonsignificant $(\beta=-.19, p=.11)$. However, because the path was theoretically important and of a magnitude that could be considered meaningful, it was retained in the final model. Consistent with our theoretical model, path estimates in the final model suggested that perceived discrimination had a significant direct negative effect on general health at the 16-week follow-up, $\beta=-.23, p=$. 05 (a slight decrease from $\beta=-.31, p<.01$, prior to the inclusion of the proposed mediators). Perceived discrimination also had a small but significant indirect negative effect on general health at 16 weeks, mediated through decreased general adherence and decreased adherence at the 16-week follow-up $(\beta=-.08, p<.05)$.

One problem with our test of this model is that it is based on a relatively small sample because of patient attrition for the 16-week follow-up. The second model we tested was identical to the one shown in Figure 1, except that general health 4 weeks after the clinic visit was substituted for general health at the 16-week follow-up, increasing the sample size to 93 patients. The model fit remained excellent: $\chi^{2}(1, N=93)=.01, p=.94 ; \mathrm{CFI}=1.0$; RMSEA $=.00(90 \% \mathrm{CI}=0.00-0.07)$. Both models show direct and indirect effects of perceived discrimination on patient health and support the role of adherence as a mediator of the discrimination health relationship. We prefer the model in Figure 1, however, because the significant path from adherence 4-weeks postinteraction to general health at the 16-week follow-up (i.e., 12 weeks later) gives us more reason to infer a causal relationship between the two measures than the latter model in which the adherence and health measures were both obtained at the same time.

\section{DISCUSSION}

We begin the discussion of the results by putting our findings in the context of other research on discrimination and health disparities. This is certainly not the first study to find a significant negative association between perceived discrimination and health among Blacks. 
Indeed, this is one of the more consistent findings in the health disparities literature (see Hausmann et al., 2008; Williams et al., 2003). Nor are we the first researchers to report negative associations between perceived discrimination and patient satisfaction with medical interactions (Benkert et al., 2006) and patient adherence to medical recommendations (Crawley et al., 2008). However, with the exception of the study by Benkert et al., most studies use responses from large national surveys and collect cross-sectional data on more or less generic measures of satisfaction and adherence. We believe that the present research represents one of the very few studies that used a longitudinal methodology to study how patients' responses to specific interactions with physicians may mediate the relationship between Black patients' experiences of being the victims of discrimination and their health. Our findings appear to identify another important way in which discrimination may harm the health of Black patients.

Overall, the current research supports previous work identifying the potential role of perceived discrimination in the health of Black Americans and in Black Americans' responses to health care. Consistent with previous research, Black patients who indicated that they had experienced higher levels of discrimination reported that they had poorer physical and mental health and actually had more chronic diseases at the time they met with a physician. In addition, higher levels of prior discrimination were negatively related to patients' previous adherence to physicians' recommendations. Moreover, patients' past experiences with discrimination predicted their responses to the interaction with the physician they encountered in the study. Patients who reported higher levels of past discrimination were (a) less satisfied with their interactions with the physicians they encountered and felt less connection (i.e., commonality) with them and (b) less likely to adhere to the recommendations they received from these physicians.

A central focus of our research was on factors that potentially mediate the relationship between prior experiences with discrimination and the later health of Black patients. Inconsistent with our expectations, satisfaction with the interaction with the physician and feelings of commonality did not mediate any of the relationships of interest in the present study. As noted earlier, research on the influence of patient satisfaction on patient adherence and health has produced mixed findings (e.g., Bogart et al., 2004; Campbell et al., 2007). Further research is needed to identify the conditions (e.g., length of relationship with the physician, the nature of the recommendations) that might moderate the relationships of patient satisfaction with patient adherence and health. Adherence, however, did have a role in the relationship of interest. That is, we found relatively strong and consistent evidence that in this study, adherence mediated the relationship between discrimination and the patients' health 4 weeks and 16 weeks after their medical interactions. Patients who believed they had frequently been the target of discrimination were less likely to adhere to physician recommendations, and this lower level of adherence was associated with subsequently poorer health. The present research thus provides direct evidence suggesting, for the first time as far as we are aware, links between patients' experience of discrimination, patient adherence to physician recommendations, and their subsequent health.

It must be emphasized, however, that while our model was strongly supported by the path analysis, this does not mean that over the short term, adherence is the most powerful determinant of a patient's health. The outcomes of a single visit to a physician rarely change a patient's overall health, and in most instances, the best predictor of the patient's health a few weeks after seeing a physician is the patient's overall health before the visit with the physician. In the present instance, by far the strongest predictor of the patients' health at the 16-week posttest was their health at the pretest. Indeed, if pretest health is added to the model presented in Figure 1, there is so little unaccounted for variance remaining that none of the other paths (including the discrimination-health path) is significant. So our position is 
not that adherence was a better short-term predictor of the patients' postvisit health status than their previsit health status. Rather, our point is that adherence does seem to be a meaningful mediator of the relationship between discrimination and health. Furthermore, it seems reasonable to argue that over the long term, this mediated relationship will significantly and substantially affect the health of Black patients.

The pattern of results revealed in the current research contributes theoretically to understanding the different ways in which the recognition of racial bias can adversely affect outcomes for Blacks. For instance, Steele (1997) has demonstrated in his work on stereotype threat how awareness of negative stereotypic expectations, without the personal endorsement of these stereotypes, can negatively affect the performance of Blacks in personally relevant and important domains (e.g., in standardized achievement tests). The core theoretical premise for our investigation was that the insidious and pervasive nature of subtle (and not-so-subtle) racism arouses distrust among Blacks, which affects their willingness to comply with the recommendations of individuals who may be seen as representative of suspect groups. That is, although in many instances nonadherence to recommendations from physicians among Blacks may be detrimental to their health (assuming, of course, that the recommendations actually have merit), it may be a quite "rational" response, given the past personal experiences of many Blacks as well as in the context of the historical legacy of racial bias in medical research and practice (Byrd \& Clayton, 2002; see also Armstrong, Crum, Reiger, Bennett, \& Edwards, 1999).

Also, although patient reactions to their interactions with physicians in the present study did not mediate the discrimination-health relationship, we believe that the negative association between perceived past discrimination and these reactions has some important theoretical and practical implications. First, the present findings regarding perceived past discrimination and the patients' reactions to the interactions replicate and extend prior work on how Blacks' expectations of bias influences the nature of their intergroup interactions (Johnson et al., 2008, Pearson et al., 2008; Shelton et al., 2005). The present study reveals that these effects also occur in more formal, relatively structured, and very consequential medical interactions as well as in the less formal and less structured kinds of interactions studied previously.

Our argument that adherence to medical recommendations is an important mediator of the perceived discrimination-health relationship among Black patients should not be seen as an alternative or competitor to other mechanisms proposed as causes of health disparities, such as discrimination as a general stressor for Blacks (see Mays et al., 2007; Williams et al., 2003). Rather, we propose adherence as an additional mechanism, which can operate in concert with other factors to negatively influence the health of Blacks. As we have noted elsewhere (Penner, Albrecht, Coleman, \& Norton, 2007), health status and health care disparities are complex, multiply determined phenomena, which require a comprehensive multielement model with several mediated pathways to identify the possible causes of health disparities, including their potentially interactive effects.

Even apparently straightforward measures, such as perceived discrimination, can operate through different psychological mechanisms. Besides the material effect of limiting a person's resources, discrimination can increase the salience of aspects of group identity, which may have some direct implications for health. For example, Oyserman, Fryberg, and Yoder (2007) found that Black university students perceived several health-promotion behaviors as reflecting a White middle-class identity, whereas unhealthy behaviors were identified with their in-group. Oyserman et al. also found that priming ethnicity increased Black students' health fatalism and reduced access to health knowledge. Thus, future research might investigate whether increasing the salience of racial identity, in ways 
independent of perceived discrimination, might affect satisfaction and adherence among Black patients in settings similar to the one we studied.

Future research might also consider more fully the role of physician race and ethnicity in the nature and outcomes of medical encounters of the type we studied. The Institute of Medicine (2003) report on racial and ethnic disparities in health and health care suggested the value of increasing the number of Black physicians for reducing Black-White health disparities.

Nevertheless, direct evidence of the role of physician race in the medical context that we examined is limited. Although the restricted number of physicians in the present research precluded definitive analysis, the results are potentially informative. In general, they reveal that greater experience of past discrimination among Black patients generally predicts less satisfaction with the subsequent medical interaction regardless of physician ethnicity/race. The correlation between Blacks' experience of discrimination and satisfaction with the medical interaction among just the patients who saw East Asian physicians was significant, $r(99)=-.23, p=.029$, and virtually identical to the correlation based on all the physicians $(-.24)$. For the very small sample of patients $(n=6)$ who saw the Black physician, the correlation was -.43 . Thus, the effects of past discrimination on Blacks' reactions to medical interactions and their physicians are not confined to just those interactions with White physicians. Perhaps this was because of how low-socioeconomic-status minority patients encounter the health care system. As was the case with the patients in this study, such patients often make appointments with a clinic not a particular physician, and frequently, they see different physicians on each visit (Doescher, Saver, Fiscella, \& Franks, 2001). Thus, there is little chance to individuate a physician. As a result, minority patients may come to see physicians more as representatives of the medical system than as unique individuals.

Future research must, however, avoid the potential pitfall of "blaming the victims." As we have noted repeatedly in this article, distrust and perceptions of racism and racial discrimination among Blacks are primarily rooted in their personal experiences of discrimination. Racism and racial discrimination in America are still pervasive and challenge Blacks on a regular basis. The present research, like research on stereotype threat (Steele, 1997), emphasizes how awareness of racism can systematically influence Blacks' behaviors in ways that can have negative consequences for Blacks. In particular, past experiences with discrimination may cause some Black patients to do things that may not be in their best health interests. Thus, we reiterate that the source of the problem is not the Black patients but the subtle and not so subtle racism they confront. Accordingly, the solutions lie not with the patients but with medical professionals and the more general society as well.

In conclusion, the present study provides yet more evidence of the deleterious effects of discrimination on Black patients' health. In addition, this research provides some new findings on the ways by which discrimination can contribute to poorer health among Blacks. Specifically, we have shown that perceived discrimination was associated with poorer adherence to physician recommendations, which was associated with poorer health. It seems very likely that this relationship has quite serious negative long-term consequences for the health of Black patients. One solution to this source of health disparities is the elimination or substantial reduction of race-based bias in the United States. However, this seems unlikely to occur any time in the near future. Thus, social scientists and health providers must develop interventions that recognize the different influences of racism on patients, providers, and their interactions to minimize the detrimental effects of perceived discrimination on the health-related behaviors of Black patients. 


\section{Acknowledgments}

This research was supported by a grant from the National Institute of Child Health and Development (1R21HD050445001A1) to Louis A. Penner, principal investigator; a grant from the National Cancer Institute (U01CA114583) to Terrance L. Albrecht and Peter Lichtenberg, principal investigators; and by a grant from the National Science Foundation (BCS-0613218) to Samuel L. Gaertner and John F. Dovidio.

\section{REFERENCES}

Anderson J. Black and blue. New Yorker. Apr 29.May 29.1996 :62-64.

Arbuckle, JL. Amos 16.0 user's guide. SPSS; Chicago: 2007.

Armstrong TD, Crum LD, Reiger RH, Bennett TA, Edwards LJ. Attitudes of African-Americans toward participation in medical research. Journal of Applied Social Psychology. 1999; 29:553-574.

Benkert R, Peters RM, Clark R, Keves-Foster K. Effects of perceived racism, cultural mistrust and trust in providers on satisfaction with care. Journal of National Medical Association. 2006; 98:1532-1540.

Bird ST, Bogart LM. Perceived race-based and socioeconomic status (SES)-based discrimination in interactions with health care providers. Ethnicity and Disease. 2001; 11:554-563. [PubMed: 11572421]

Blanchard JC, Lurie N. R-E-S-P-E-C-T: Patient reports of disrespect in the healthcare setting and its impact on care. Journal of Family Practice. 2004; 53:721-730. [PubMed: 15353162]

Bobo, L. Racial attitudes and relations at the close of the twentieth century.. In: Smelser, NJ.; Wilson, WJ.; Mitchell, F., editors. Racial trends and their consequences. Vol. 1. National Academies Press; Washington, DC: 2001. p. 264-301.

Bogart LM, Bird ST, Walt LC, Delahanty DL, Figler JL. Association of stereotypes about physicians to health care satisfaction, help-seeking behavior, and adherence to treatment. Social Science and Medicine. 2004; 58:1049-1058. [PubMed: 14723901]

Bollen, KA. Structural equations with latent variables. John Wiley; New York: 1989.

Brown TN. Measuring self-perceived racial and ethnic discrimination in social surveys. Sociological Spectrum. 2001; 21:377-392.

Buskirk TD, Stein KD. Telephone vs. mail survey gives different SF-36 quality-of-life scores among cancer survivors. Journal of Clinical Epidemiology. 2008; 61:1049-1055. [PubMed: 18538997]

Byrd, WM.; Clayton, LA. An American health dilemma: A medical history of African Americans and the problem of race. Routledge; New York: 2002.

Campbell TA, Auerbach SM, Kiesler DJ. Relationship of interpersonal behaviors and health-related control appraisals to patient satisfaction and compliance in a university health center. Journal of American College Health. 2007; 55:333-340. [PubMed: 17517545]

Clark R, Anderson N, Clark VR, Williams DR. Racism as a stressor for African Americans: A biopsychosocial model. American Psychologist. 1999; 54:805-816. [PubMed: 10540593]

Cozier YC, Palmer JR, Horton NJ, Fredman L, Wise LA, Rosenberg L. Relation between neighborhood median housing value and hypertension risk among black women in the United States. American Journal of Public Health. 2007; 97:718-724. [PubMed: 17329664]

Crawley LM, Ahn DK, Winkleby MA. Perceived medical discrimination and cancer screening behaviors of racial and ethnic minority adults. Cancer Epidemiology Biomarkers and Prevention. 2008; 17:1937-1943.

Crocker J, Luhtanen R, Broadnax S, Blaine BE. Belief in U.S. government conspiracies against Blacks among Black and White college students: Powerlessness or system blame? Personality and Social Psychology Bulletin. 1999; 25:941-953.

Diez-Roux AV, Merkin SS, Arnett D, Chambless L, Massing M, Nieto FJ, et al. Neighborhood of residence and incidence of coronary heart disease. New England Journal of Medicine. 2001; 345:99-106. [PubMed: 11450679]

Doescher MP, Saver BG, Fiscella K, Franks P. Racial/ethnic inequities in continuity and site of care: Location, location, location. Health Services Research. 2001; 36:78-89. [PubMed: 16148962] 
Dovidio, JF.; Gaertner, SL. Aversive racism.. In: Zanna, MP., editor. Advances in experimental social psychology. Vol. 36. Academic Press; San Diego, CA: 2004. p. 1-51.

Dovidio JF, Gaertner SL, Kawakami K, Hodson G. Why can't we just get along? Interpersonal biases and interracial distrust. Cultural Diversity \& Ethnic Minority Psychology. 2002; 8:88-102. [PubMed: 11987594]

Dovidio JF, Kawakami K, Gaertner SL. Implicit and explicit prejudice and interracial interaction. Journal of Personality and Social Psychology. 2002; 82:62-68. [PubMed: 11811635]

Dovidio JF, Penner LA, Albrecht TL, Norton WE, Gaertner SL, Shelton JN. Disparities and distrust: The implications of psychological processes for understanding racial disparities in health and health care. Social Science and Medicine. 2008; 67:478-486. [PubMed: 18508171]

Epstein RM, Franks P, Fiscella K, Shields CG, Meldrum SC, Kravitz RL, et al. Measuring patientcentered communication in patient-physician consultations: Theoretical and practical issues. Social Science and Medicine. 2005; 61:1516-1528. [PubMed: 16005784]

Gaertner, SL.; Dovidio, JF. The aversive form of racism.. In: Dovidio, JF.; Gaertner, SL., editors. Prejudice, discrimination, and racism. Academic Press; Orlando, FL: 1986. p. 61-89.

Gaertner, SL.; Dovidio, JF. Reducing intergroup bias: The common ingroup identity model. Psychology Press; Philadelphia: 2000.

Greenwald AG, Nosek BA, Banaji MR. Understanding and using the Implicit Association Test: I. An improved scoring algorithm. Journal of Personality and Social Psychology. 2003; 85:197-216. [PubMed: 12916565]

Halbert CH, Armstrong K, Gandy OH, Shaker L. Racial differences in trust in health care providers. Archives of Internal Medicine. 2006; 166:896-901. [PubMed: 16636216]

Harris LE, Luft FC, Rudy DW, Tierney WM. Correlates of health care satisfaction in inner-city patients with hypertension and chronic renal insufficiency. Social Science and Medicine. 1995; 4:1639-1645. [PubMed: 8746863]

Hausmann LR, Jeong K, Bost JE, Ibrahim SA. Perceived discrimination in health care and health status in a racially diverse sample. Medical Care. 2008; 46:905-914. [PubMed: 18725844]

Hays RD, Kravitz RL, Mazel RM, Sherbourne CD, DiMatteo MR, Rogers WH, et al. The impact of patient adherence on health outcomes for patients with chronic disease in the Medical Outcomes Study. Journal of Behavioral Medicine. 1994; 17:347-360. [PubMed: 7966257]

$\mathrm{Hu}$ L, Bentler PM. Cutoff criteria for fit indexes in covariance structure analysis: Conventional criteria versus new alternatives. Structural Equation Modeling. 1999; 6:1-55.

Institute of Medicine. Unequal treatment: Confronting racial and ethnic disparities in health care. Smedley, BD.; Stith, AY.; Nelson, AR., editors. National Academies Press; Washington, DC: 2003.

Johnson JD, Ashburn-Nardo L, Spicer CV, Dovidio JF. The role of Blacks' discriminatory expectations on prosocial orientations towards Whites and Blacks. Journal of Experimental Social Psychology. 2008; 44:1498-1505.

Johnson RL, Saha S, Arbelaez JJ, Beach MC, Cooper LA. Racial and ethnic differences in patient perceptions of bias and cultural competence in health care. Journal of General Internal Medicine. 2004; 19:101-110. [PubMed: 15009789]

Kline, RB. Principles and practice of structural equation modeling. 2nd ed.. Guilford; New York: 2005.

Lee JS, Tamayo-Sarver J, Kineer P, Hobgood C. Association between patient race/ethnicity and perceived interpersonal aspects of care in the emergency department. Journal of the National Medical Association. 2008; 100:79-85. [PubMed: 18277813]

Liang K-Y, Zeger SL. Longitudinal data analysis using generalized linear models. Biometrika. 1986; 73:13-22.

Little P, Everitt H, Williamson I, Warner G, Moore M, Gould C, et al. Preferences of patients for patient centred approach to consultation in primary care: Observational study. British Medical Journal. 2001; 24:468-472. [PubMed: 11222423]

Malat J, Hamilton MA. Preference for same-race health care providers and perceptions of interpersonal discrimination in health care. Journal of Health and Social Behavior. 2006; 47:173187. [PubMed: 16821510] 
Mallinger JB, Griggs JJ, Shields CG. Patient-centered care and breast cancer survivors' satisfaction with information. Patient Education and Counseling. 2005; 57:342-359. [PubMed: 15893218]

Mays VM, Cochran SD, Barnes N. Race, racism and the health outcomes among African Americans. Annual Review of Psychology. 2007; 58:565-592.

McConahay, JB. Modern racism, ambivalence, and the Modern Racism Scale.. In: Dovidio, JF.; Gaertner, SL., editors. Prejudice, discrimination, and racism. Academic Press; Orlando, FL: 1986. p. 99-125.

McConnell AR, Leibold JM. Relations among the implicit association test, discriminatory behavior, and explicit measures of racial attitudes. Journal of Experimental Social Psychology. 2001; 37:435-442.

Morisky DE, Ang A, Krousel-Wood M, Ward HJ. Predictive validity of a medication adherence measure in an outpatient setting. Journal of Clinical Hypertension. 2008; 10:348-354. [PubMed: 18453793]

Nevitt J, Hancock GR. Performance of bootstrapping approaches to model test statistics and parameter standard error estimation in structural equation modeling. Structural Equation Modeling. 2001; 8:353-377.

Oyserman D, Fryberg S, Yoder N. Identity-based motivation and health. Journal of Personality and Social Psychology. 2007; 93:1011-1027. [PubMed: 18072851]

Pearson AR, West TV, Dovidio JF, Powers SR, Buck R, Henning RA. The fragility of intergroup relations: Divergent effects of delayed audio-visual feedback in intergroup and intragroup interaction. Psychological Science. 2008; 19:1272-1279. [PubMed: 19121137]

Penner LA, Albrecht TL, Coleman D, Norton WE. Interpersonal perspectives on Black-White health disparities: Social policy implications. Social Issues \& Policy Review. 2007; 1:63-98.

Phelps RE, Taylor JD, Gerard PA. Cultural mistrust, ethnic identity, racial identity and self-esteem among ethnically diverse black students. Journal of Counseling \& Development. 2001; 79:209_ 216.

Ryan AM, Gee GC, Griffith D. The effects of perceived discrimination on diabetes management. Journal of Health Care for the Poor and Underserved. 2008; 19:49-63.

Saad, L. [August 30, 2008] A downturn in Black perceptions of racial harmony. 2007. from http:// www.gallup.com/poll/28072/Downturn-Black-Perceptions-Racial-Harmony.aspx

Schuman, H.; Steeh, C.; Bobo, L.; Krysan, M. Racial attitudes in America: Trends and interpretations. Harvard University Press; Cambridge, MA: 1997.

Sears, DO.; Henry, PJ.; Kosterman, R. Egalitarian values and the origins of contemporary American racism.. In: Sears, DO.; Sidanius, J.; Bobo, L., editors. Racialized politics: The debate about racism in America. University of Chicago Press; Chicago: 2000. p. 75-117.

Shelton JN, Richeson JA, Salvatore J. Expecting to be the target of prejudice: Implications for interethnic interactions. Personality and Social Psychology Bulletin. 2005; 31:1189-1202. [PubMed: 16055639]

Shelton JN, Richeson JA, Vorauer JD. Threatened identities and interethnic interactions. European Review of Social Psychology. 2006; 17:321-358.

Steele CM. A threat in the air: How stereotypes shape intellectual identity and performance. American Psychologist. 1997; 52:613-629. [PubMed: 9174398]

Stewart M, Brown JB, Donner A, McWhinney IR, Oates J, Weston WW, et al. The impact of patientcentered care on outcomes. Journal of Family Practice. 2000; 49:796-804. [PubMed: 11032203]

Sue DW, Capodilupo CM, Torino GC, Bucceri JM, Holder AMB, Nadal KL, et al. Racial microaggressions in everyday life: Implications for clinical practice. American Psychologist. 2007; 62:271-286. [PubMed: 17516773]

Thorburn S, Bogart LM. African American women and family planning services: Perception of discrimination. Women and Health. 2005; 42:23-39. [PubMed: 16418120]

Trivedi AN, Ayanian JZ. Perceived discrimination and use of preventive health services. Journal of General Internal Medicine. 2006; 21:553-558. [PubMed: 16808735]

Ware, JE.; Sherbourne, CD.; Davies, AR. Developing and testing the MOS 20-item short-form health survey: A general population application.. In: Stewart, AL.; Ware, JE., editors. Measuring 
functioning and well-being: The Medical Outcomes Study approach. Duke University Press; Durham, NC: 1992. p. 277-290.

Williams D, Yu Y, Jackson J, Anderson N. Racial differences in physical and mental health:

Socioeconomic status, stress, and discrimination. Journal of Health Psychology. 1997; 2:335-341. [PubMed: 22013026]

Williams DR, Neighbors HW, Jackson JS. Racial/ethnic discrimination and health: Findings from community studies. American Journal of Public Health. 2003; 93:200-208. [PubMed: 12554570]

Wroth TH, Pathman DE. Primary medication adherence in a rural population: The role of the patientphysician relationship and satisfaction with care. Journal of American Board of Family Medicine. 2006; 19:478-486. 


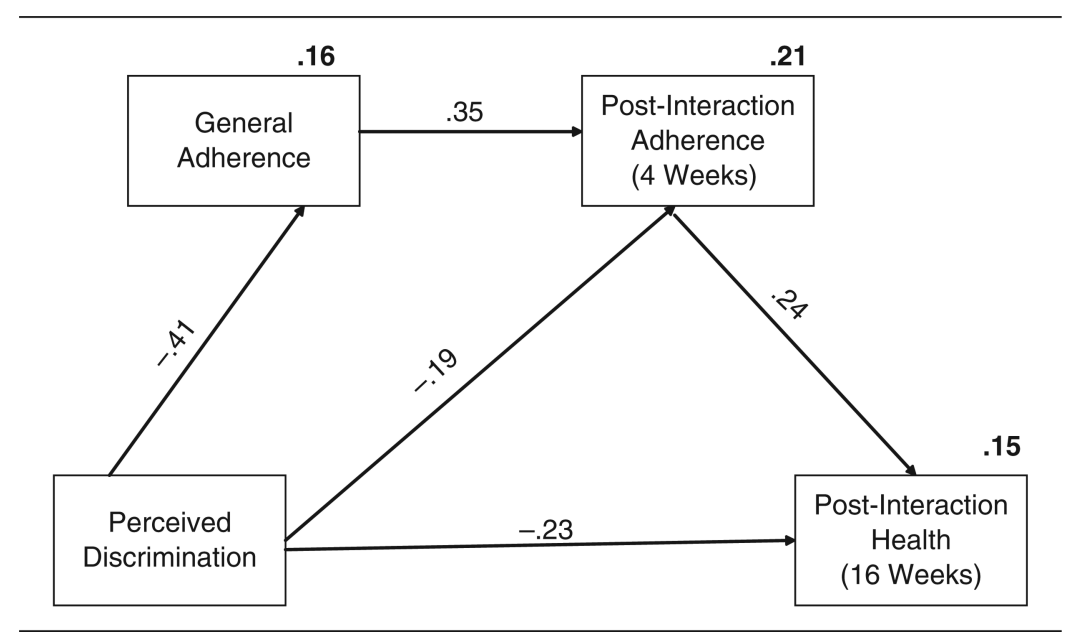

Figure 1. Path Model of the Effects of Discrimination History on Health 16 Weeks After the Medical Interaction

NOTE: The bolded value on the top right corner of each endogenous variable denotes the proportion of variance explained in that variable. All other values represent standardized path coefficients. 
